\title{
New advances in the treatment of adult chronic immune thrombocytopenic purpura: role of thrombopoietin receptor-stimulating agents
}

This article was published in the following Dove Press journal:

Biologics: Targets \& Therapy

3 December 2009

Number of times this article has been viewed

\author{
Ara Metjian' \\ Charles S Abrams ${ }^{2}$ \\ 'Department of Medicine, Duke \\ University Medical Center, Durham, \\ NC, USA; ${ }^{2}$ Department of Medicine, \\ University of Pennsylvania, \\ Philadelphia, PA, USA
}

\begin{abstract}
Decades of basic science and clinical research have led to an increased understanding of the pathophysiology of immune thrombocytopenic purpura (ITP), the processes underlying thrombopoiesis, and the treatment of chronic ITP. Now, new agents are available to treat ITP in a nonimmunosuppressive fashion. Lessons learned from the clinical trials of recombinant human thrombopoietin (TPO) have led to the development of a novel class of compounds: nonimmunogenic agonists of the thrombopoietin receptor. Representing the first nonimmunosuppressive agents to treat chronic refractory ITP in decades, medications such as romiplostim and eltrombopag were recently approved by the US Food and Drug Administration. These new agents offer physicians a new tool for treating difficult cases of ITP in their medical armamentarium. Additional TPO mimetics are also being developed that show promise in vitro, and await future development.
\end{abstract}

Keywords: thrombocytopenia, immune-mediated thrombocytopenia, eltrombopag, romiplostim, thrombopoietin, thrombopoietin receptor

\section{Introduction}

When platelets fall below $150,000 / \mu 1$, a patient is considered to have thrombocytopenia. Hemostasis can become compromised when the platelet count falls to less than $50,000 / \mu 1$ and the risk for spontaneous hemorrhage is significantly increased at levels less than 20,000/ $\mu 1$. While the causes and diagnostic algorithms for thrombocytopenia are beyond the scope of this review, it can be delineated to three broad categories: 1) increased destruction, as seen in immune thrombocytopenic purpura (ITP) or disseminated intravascular coagulation, 2) decreased production, due to aplastic anemia or some other bone marrow production disorder, or 3) sequestration, as occurs in conditions leading to splenomegaly.

Because the differential diagnosis and treatment for thrombocytopenia is so extensive and varied, a thorough history and physical examination, with attention to possible alternative explanations for thrombocytopenia is mandatory. Preliminary laboratory tests include a complete blood count with a differential, along with an examination of the peripheral blood smear. Any additional testing is based solely upon the available clinical information, eg, human immunodeficiency virus (HIV) testing in a patient with risk factors. Bone marrow biopsy should be reserved for older patients or in the evaluation of patients in whom standard therapy has not been effective. Determining the etiology of thrombocytopenia is essential in order to provide the proper treatment and to avoid unnecessary procedures and treatments. ${ }^{1,2}$ since the diagnosis of ITP remains one of exclusion. ${ }^{3}$ In order to understand the rationale of ITP treatment, a review of its
Correspondence: Charles S Abrams Hematology-Oncology Division, University of Pennsylvania School of Medicine, 42I Curie Blvd., Biomedical Research Building II/III, \#9|2, Philadelphia, PA 19104

Tel + I 2158981058

Fax +I 2155737400

Email abrams@mail.med.upenn.edu 
history and advances in understanding the pathophysiology of this condition is necessary.

\section{History of ITP treatment}

Splenectomy was considered to be the first published treatment for ITP, which was reported in 1916 by Kaznelson in Prague, as reviewed by Whipple. ${ }^{4}$ In Whipple's review, Kaznelson reported 81 cases of thrombocytopenia, and he noted that splenectomy is "considered the greatest advance to the therapy of the purpuras" but he forewarned, "it should be emphasized that the patients after splenectomy should be cautioned and guarded against infections in order to obtain the best results."

Splenectomy remained the sole treatment for ITP for over a quarter of a century until the introduction of corticosteroids in clinical practice. Adrenocorticotropic hormone (ACTH) was discovered to be effective for ITP, ${ }^{5}$ and later cortisone, ${ }^{6}$ supplanting splenectomy as the primary treatment for ITP. Given that clinical remissions were possible with corticosteroids, their use remained the initial treatment choice for ITP for more than 50 years. The use of immunomodulatory agents in ITP was augmented by intravenous immunoglobulin (IVIg) or anti-D, and by alternative immunosuppressives for refractory ITP, such as cyclophosphamide, ${ }^{7}$ azathioprine, ${ }^{8}$ interferon (IFN), ${ }^{9}$ cyclosporine A, ${ }^{10}$ mycophenolate mofetil, ${ }^{11}$ dapsone, ${ }^{12}$ and etanercept. ${ }^{13}$ While danazol has also been used to treat refractory ITP, ${ }^{14}$ it is an attenuated androgen, and therefore, not an immunosuppressive in the conventional sense. The use of these alternative immunosuppressants and immunomodulators in chronic refractory ITP has been expertly summarized elsewhere. ${ }^{15}$

Since immunomodulation was the only effective treatment of ITP, use of immunosuppressive agents, splenectomy, or immune modulators such as IVIg or anti-D was all that was available. Despite the many immunomodulatory agents that were available, a pressing need for alternative treatments arose. This stemmed from the significant percentage of patients who relapsed after steroid taper, failed to respond to splenectomy, and who developed chronic and refractory thrombocytopenia. ${ }^{3}$ This challenging cohort of patients often have mortality related to the immunosuppression caused by the medications used to treat the thrombocytopenia than from bleeding. ${ }^{16}$ This leaves affected patients feeling that the treatment is often worse than the disease. ${ }^{17}$ For example, cyclophosphamide, azathioprine, and mycophenolate are immunosuppressive agents associated with an increased risk of infection in splenectomized patients. Danazol can lead to unfavorable lipid profiles, and can have virilizing effects on female patients. The limited efficacy of third line agents, along with the undesirable and potentially lethal side effects of commonly used immunosuppressives, helped spur research into discovering the complicated mechanisms of ITP.

\section{Platelet underproduction in ITP}

When bone marrow studies are performed on ITP patients, megakaryocyte hyperplasia is often noted, despite the decreased peripheral count. This observation led to the interpretation that despite the increase in the production of platelets, the peripheral destruction of platelets is able to out-pace their production, ultimately leading to thrombocytopenia. With refined research techniques over the ensuing decades, a number of observations called into question the validity of these suppositions, which ultimately has set the stage for the rationale and development of thrombopoietin (TPO) mimetics.

An early report noted that the megakaryocytes within the bone marrow of ITP patients were increased in number. ${ }^{18}$ However, when compared to the bone marrow of patients with secondary forms of thrombocytopenia, eg, cirrhosis with splenomegaly, the megakaryocytes of both acute and chronic ITP patients were observed to have a reduction in platelet production. This observation of platelet hypo-production had gone largely unnoticed, until platelet kinetic studies suggested and then helped elucidate the degree of bone marrow response in ITP.

In 1985, Stoll and colleagues examined the average life-span of platelets in patients with a moderate degree of thrombocytopenia with ITP. ${ }^{19}$ Autologous platelets labeled with ${ }^{51}$ Chromium $\left({ }^{51} \mathrm{Cr}\right)$ were used instead of heterologous ${ }^{51} \mathrm{Cr}$-labeled platelets. When compared to normal volunteers, the average life of the labeled platelet was reduced. However, the investigators noted that the rate of platelet production was practically equivalent to that of the normal volunteers, concluding that the rate of platelet production was not increased in ITP. ${ }^{19}$ With the use of ${ }^{111}$ Indium-labeled platelets, it was observed that the platelet life-span was not as short as previously thought, ${ }^{20}$ and that the majority of patients with ITP did not have an increase in platelet production. ${ }^{21}$ This has led investigators to conclude that despite the hyperplasia of megakaryocytes in the bone marrow, "the predominant cause of thrombocytopenia is ineffective marrow platelet production rather than accelerated platelet removal". ${ }^{22}$ It should be noted that many patients enrolled in this trial had very mild ITP, and the few patients with severe ITP, who were studied by this method did have markedly shortened platelet 
survival. Therefore, one can conclude that platelet survival is variable in ITP; however, most patients with significant thrombocytopenia do have enhanced peripheral destruction of their platelets.

\section{Discovery of thrombopoietin and its receptor}

After the discovery of erythropoietin (Epo), it was extrapolated that another humoral agent should exist which increases the platelet count. The term "thrombopoietin" was first used in 1958, when it was observed that sera injected into mice from patients with thrombocytosis caused an increase in the platelet count. This unknown substance was characterized as a protein, and the authors concluded that this serum "thrombopoietin" existed in equilibrium with an inhibitor. ${ }^{23}$ Further evidence for this equilibrium was observed when researchers transfused "viable platelets" into thrombocytopenic rats, with subsequent diminution of thrombopoiesis. Based upon these experiments and observations, the authors accurately postulated nearly half a century ago that "platelet production is regulated by the circulating platelets themselves". ${ }^{24}$

Meanwhile, the search for the proposed "thrombopoietin" continued for more than 40 years, and numerous cytokines were proposed as possible candidates, among which included interleukin (IL)-1 $\alpha$, IL-6, and IL-11. While these cytokines were capable of increasing the platelet count, it was not until the identification of murine leukemia virus that the discovery of TPO was accomplished.

\section{Discovery of the thrombopoietin receptor, $\mathrm{Mpl}$}

In 1986, researchers in France found a variant of the Friend helper ecotropic virus, one that caused thrombocytosis instead of pancytopenia in mice. It was named myleproliferative leukemia virus (MPLV), the genome of this virus contained a novel oncogene, $v-m p l$, that was found to have a well conserved mammalian homolog, $c$ - $m p l$, which mapped to chromosome $1 \mathrm{p} 34 .{ }^{25,26}$ When transfected into mammalian bone marrow cells, expression of $v-m p l$ caused their immortalization, and when $c-m p l$ was eventually cloned, it was found to have sequence homology with the hematopoietic receptor superfamily. ${ }^{27,28}$ Antagonism of $c-m p l$ via anti-sense DNA technology led to a reduction in megakaryocyte colony forming units, but not in the erythroid or granulocytic lineages. This showed that proper function of $c-m p l$ was crucial for the production of platelets, and likely the receptor for an unknown ligand required for thrombopoiesis. ${ }^{29}$ Additional evidence from these $c$ - $m p l$ knock-out mice revealed they had normal levels of red and white cells, but had an $85 \%$ decrease in platelet levels. ${ }^{30}$ Further study of these $c$-mpl knock-out mice suggested that $\mathrm{Mpl}$, in addition to playing an important role in the later stages of megakaryocyte production and maturation, may also play a key role in the production and regulation of bone marrow stem cells..$^{31,32}$

\section{Finding and characterizing TPO}

Although the search for TPO had been undertaken for decades, several groups working independently published their findings in the cloning of the $c-m p l$ ligand, which was eventually termed thrombopoietin (TPO). ${ }^{33-36}$ Initial studies showed that TPO increased the platelet counts of mice, promoted the proliferation and differentiation of megakaryocytes, and mapped to chromosome $3 \mathrm{q} 27.37,38$ In addition to increasing platelet production, TPO was observed to affect the longevity and proliferation of hematopoietic stem cells. ${ }^{39}$ Working in concert with Epo, stem cell factor, and IL-11, TPO is an integral factor in megakaryocyte growth, development, and increases the nuclear ploidy of the maturing megakaryocyte. ${ }^{40}$ After thrombopoiesis has occurred, TPO continues to play a role in platelet signaling. Under physiologic concentrations, TPO "primes" the platelet to be more sensitized to the effects of thrombin, leading to improved platelet aggregation and secretion. ${ }^{41,42}$

\section{Cellular effects of TPO binding to Mpl}

When TPO binds to Mpl, several intracellular signaling cascades occur. While a complete review is beyond the scope of this article, and has been expertly reviewed elsewhere, ${ }^{43}$ a brief description follows.

Upon TPO binding with Mpl, the receptor undergoes homo-dimerization, ${ }^{44}$ which is thought to initiate the intracellular signaling cascade. Janus kinase 2 (JAK2) is rapidly activated via transphosphorylation, and phosphorylates $\mathrm{Mpl}$ on tyrosine-112, which is necessary for intracellular signaling. The phosphorylation of serine-18, which is required for binding of phospho-JAK2 occurs by an undetermined kinase. ${ }^{45-47}$ The phosphorylation of $\mathrm{Mpl}$ facilitates binding of Src homology 2 (SH2) signaling adaptor proteins. This enhances the binding of the signal transducers and activators of transcription (STAT), specifically STAT3 and STAT5 in Mpl cells. ${ }^{48,49}$ These in turn are phosphorylated by JAK-2, causing STAT3/STAT5 to dimerize and translocate to the nucleus, leading to their effects upon transcription. ${ }^{43}$ Other proteins that have been implicated in binding via their $\mathrm{SH} 2$ domains to Mpl include Shc, Vav, Grb2, SHIP, and SOS, among others. ${ }^{50,51}$ 
In addition to the binding of $\mathrm{SH} 2$ proteins, phosphorylated Mpl creates a binding site for Shc, which is then phosphorylated ${ }^{45,49}$ and recruits Grb2 and Sos. This leads to Ras activation, ${ }^{49}$ recruiting Raf, with subsequent activation of mitogen-activated protein kinase (MAPK)/extracellularsignal receptor kinase (ERK). ${ }^{50}$ Activation of MAPK leads to megakaryocyte development, an increase in nuclear ploidy, and endomitosis. ${ }^{52,53}$

While not completely understood, TPO stimulated activation of Mpl leads to the activation of phosphatidylinositol-3 kinase (PI3K). This enzyme catalyzes the phosphorylation of PI4P and PI4,5P to make PI-3,4P2 and PI-3,4,5P3, respectively. Once created in the cellular membrane, these phospholipids allow for the docking of proteins with pleckstrin homology $(\mathrm{PH})$ domains. Key among these phosphatidylinositol-binding proteins is the Akt kinase, a protein that contributes to numerous cellular events affecting proliferation and survival. ${ }^{43} \mathrm{PI} 3 \mathrm{~K}$, with its adaptor protein p85, associates with Gab2 and IRS2. This also leads to the activation of ERK in a Ras-independent fashion.

\section{TPO in disease states}

In chemotherapy-induced thrombocytopenia (CIT), TPO levels were noted to be elevated. ${ }^{54}$ By comparing it to the physiologic behavior of Epo, it was inferred that in thrombocytopenic states, levels of TPO would be increased, just as is seen in certain forms of anemia. As might be expected, TPO levels were elevated in aplastic anemia and acute lymphoblastic leukemia, whereas the TPO concentration in essential thrombocytosis were not raised. ${ }^{55}$ However, when levels of TPO were examined in patients with ITP, TPO levels were observed to be within the normal range. This raised the possibility that part of the defect in ITP may be due to a lack of elevated TPO levels. ${ }^{56,57}$ These observations were difficult to reconcile with the prevailing notion that TPO functioned in a fashion similar to Epo, especially when megakaryocyte hyperplasia was noted on bone marrow biopsies. Yet, these observations fueled further study into the mechanisms of platelet production.

Using distinct patient populations with thrombocytopenia, TPO levels were examined in patients with aplastic anemia, ITP, post-transfusion purpura (PTP), drug purpura (DP), and X-linked thrombocytopenia (XLTP). These values were compared to the platelet count and megakaryocyte mass, whereupon it was observed that patients with ITP, PTP, DP, and XLTP had seemingly inappropriately low TPO levels. ${ }^{58}$ It has also been observed that leukemic myeloid cells with a functional Mpl, bound TPO and lowered its circulating level, which returned to normal levels following induction chemotherapy. ${ }^{59}$ The observations in the different TPO levels could be explained by the relative increase in megakaryocyte mass that has been noted in the specific low TPO states, an observation that has been well-known in ITP.

This, along with numerous other observations, have confirmed a model for TPO production and regulation nearly thirty years after it was first proposed. ${ }^{60}$ The majority of TPO is constitutively produced by the liver, and to a lesser extent the kidneys and bone marrow stroma. Circulating platelets and bone marrow megakaryocyte mass directly regulate TPO levels by internalizing receptor bound $\mathrm{TPO}^{61}$ and degrading it, instead of modifying TPO production or release. ${ }^{62,63}$ Therefore, an increase in either platelet or megakaryocyte mass causes a decrease in the circulating TPO level. ${ }^{43}$ This so-called "sponge theory" 64 of TPO regulation is analogous to the neutrophil granulocyte-colony stimulating factor (G-CSF) receptor-mediated clearance of G-CSF. ${ }^{65}$

\section{From bench to bedside: The use of recombinant TPO to treat thrombocytopenia}

Once the sequence for TPO became known, recombinant versions were created to use clinically. Two forms were tested in a variety of circumstances: recombinant human (rhTPO) and polyethylene glycol recombinant megakaryocyte growth and development factor (PEG-rHuMGDF). rhTPO is a fulllength glycosylated form of TPO. ${ }^{66}$ The PEG-rHuMGDF is a recombinant truncated fragment of TPO that still has the ability to bind and activate $\mathrm{Mpl},{ }^{67}$ with the linkage to PEG that greatly enhances its half-life. ${ }^{68,69}$ Both rhTPO and PEGrHuMGDF produce robust increases in platelet counts after a delay of 4-6 days, and have prolonged half-lives. ${ }^{70}$

\section{Nonmyeloablative chemotherapy-induced thrombocytopenia}

In addition to leukopenia caused by nonmyeloablative chemotherapy, CIT is a common complication. A clinical trial examined the role of recombinant TPO's in treating thrombocytopenia resulting from carboplatin and paclitaxel in advanced lung cancer treatment. It was observed that PEGrHuMGDF-treated study subjects had less of a nadir platelet count, and recovery to base-line levels were hastened by therapy with little adverse effects. ${ }^{69}$ Similar benefits were also shown in patients who received carboplatin for treatment of gynecologic cancers. ${ }^{71}$ In a phase I/II study of patients undergoing treatment with chemotherapy for sarcoma, patients given 
a single intravenous dose of rhTPO demonstrated increased platelet counts by day 4 , and peak platelet counts between days 10-15 before returning towards baseline. Although rhTPO was generally well tolerated, one patient transiently developed an antibody against TPO. ${ }^{72}$ However, there is no evidence or recommendations for the use of thrombopoiesis-stimulating agents in this setting, as exists for G-CSF.

\section{Use in thrombocytopenia of HIV}

The use of recombinant TPO's was investigated in thrombocytopenic patients with HIV. Initially, PEG-rHuMGDF was tested in HIV-infected chimpanzees, with encouraging results. ${ }^{73}$ Three doses of PEG-rHuMGDF produced a 10 -fold increase in the platelet count, along with a 30 -fold increase in megakaryocytes. ${ }^{73}$ These experiments led to an early clinical trial in six patients with HIV and thrombocytopenia. This study demonstrated that a $5 \mu \mathrm{g} / \mathrm{kg} /$ dose administered subcutaneously twice weekly produced a 10 -fold increase in platelet number within two weeks of treatment. This increased platelet count persisted throughout the 16 weeks of treatment, but returned to the thrombocytopenic levels within two weeks of cessation of therapy. ${ }^{74}$

\section{Enhancing yields in platelet donation}

PEG-rHuMGDF was also evaluated in clinical trials to determine if it could increase the amount of platelets collected during a donation. In a set of companion studies, ${ }^{75,76}$ healthy platelet donors were treated with a single injection of placebo, $1 \mu \mathrm{g} / \mathrm{kg}$, or $3 \mu \mathrm{g} / \mathrm{kg}$ of PEG-rHuMGDF. Platelets collected via apheresis were then transfused to adult patients, who required prophylactic platelet transfusions as a result of CIT. The initial phase of the study found that platelet donors treated with PEG-rHuMGDF, as expected, achieved higher platelet counts in a dose dependent fashion. Furthermore, a higher number of platelets were collected at greater collection efficiency when compared to placebo. The volunteers tolerated the treatment well, with only headache reported as a side effect. ${ }^{75}$ The latter phase of these two studies examined the efficacy of the platelets that were obtained from pretreated donors in patients with CIT. ${ }^{76}$ It was observed that the thrombocytopenic patients who received platelets from PEG-rHuMGDF treated donors, had higher post-transfusion counts, and were able to go longer until receiving the next platelet transfusion. ${ }^{76}$

\section{A novel treatment option for ITP}

PEG-rHuMGDF and rhTPO were also tested in the treatment of chronic refractory ITP. Three out of four patients with ITP who were given $0.5 \mu \mathrm{g} / \mathrm{kg}$ /day of PEG-rHuMGDF for up to seven days had an increase in their platelet counts. The one subject whose platelets did not rise, had a decrease in bleeding episodes. ${ }^{77}$ PEG-rHuMGDF was also used to treat a rare variant of ITP, cyclic thrombocytopenia. In the treatment of a refractory patient, who had hemorrhagic symptoms for almost 50 years, despite numerous immunosuppressive medications, PEG-rHuMGDF was effective in inducing safe platelet levels without significant side effects. ${ }^{78}$ rhTPO was used successfully in the treatment of a 41-year-old woman with chronic refractory ITP. Notably, this patient became less responsive, and for shorter durations with each successive cycle of rhTPO therapy even though antibodies to rhTPO or endogenous TPO were never detected. ${ }^{79}$

\section{Myelodysplastic syndrome and aplastic anemia}

Preliminary studies have evaluated the use of PEG-rHuMGDF for the treatment of myelodysplastic syndrome (MDS) and aplastic anemia. In vitro laboratory data reveals that when bone marrow cells harvested from patients with MDS are incubated with TPO, granulocyte and erythroid precursors are stimulated. This raises the possibility that administration of this growth factor may stimulate the malignant clones in the bone marrow. ${ }^{80,81}$ Yet despite this potential drawback, limited human data with the use of TPO agents gives hope for cautious optimism. An isolated case report in a thrombocytopenic woman treated with PEG-rHuMGDF for over a year demonstrated an increase in both platelet and red cell counts. ${ }^{82}$ Shortly after this publication, another case report detailed the use of PEG-rHuMGDF in aplastic anemia. In this situation, daily administration of PEG-rHuMGDF led to a tri-lineage response, eliminating the need for transfusions or additional treatment. ${ }^{83}$

\section{Use in myeloablative chemotherapy}

The first human trial of PEG-rHuMGDF in the setting of induction and consolidation chemotherapy in acute myelogenous leukemia (AML) involved 108 adult AML patients. They were randomized to receive placebo, a single dose for seven days, or 21 days of PEG-rHuMGDF. ${ }^{84}$ Although PEG-rHuMGDF was well tolerated, and did not stimulate the growth of leukemic cells, it did not shorten the duration of the platelet transfusion-dependent period (the primary endpoint). In this trial, PEG-rHuMGDF enhanced the rebound thrombocytosis upon platelet count recovery. In another de novo trial of AML patients who were treated at the end of induction or consolidation chemotherapy with placebo, 
$2.5 \mu \mathrm{g} / \mathrm{kg} / \mathrm{day}$, or $5 \mu \mathrm{g} / \mathrm{kg} /$ day of PEG-rHuMGDF, also had disappointing results. ${ }^{85}$ Although recovery thrombocytosis was highest among the $5 \mu \mathrm{g} / \mathrm{kg} /$ day group, there were no significant benefits to patients receiving PEG-rHuMGDF with respect to the number of platelet transfusions required or the duration of the platelet nadir. A similar lack of benefit was also seen in patients with advanced breast cancer, who were undergoing autologous bone marrow transplant. ${ }^{86}$ In this trial, patients were randomized to receive either placebo, 1.0, 2.5, $5.0,7.5$, or $10.0 \mu \mathrm{g} / \mathrm{kg} / \mathrm{day}$, starting on the day of transplantation until platelet counts recovered, or for 21 days. Although well tolerated, even the highest dose of PEG-rHuMGDF failed to induce earlier platelet engraftment.

\section{The demise of recombinant TPO}

The initial studies of the recombinant TPO's showed that they have enormous potential in raising the platelet count in a variety of conditions associated with thrombocytopenia. Unfortunately, it was noted that patients and healthy volunteers developed antibodies not only against the exogenously administered PEG-rHuMGDF, but also against endogenous TPO. These anti-TPO antibodies resulted in sustained thrombocytopenia. ${ }^{87}$ Similarly, 13 of the 325 healthy volunteers, and 4 of the 650 oncology patients treated with PEG-rHuMGDF developed persistent thrombocytopenia attributable to immune responses against the drug, as well as against endogenous TPO. In addition to thrombocytopenia, pancytopenia developed in a patient who had received PEG-rHuMGDF with six cycles of chemotherapy. ${ }^{88}$ Almost all of these reactions were seen in patients treated with PEG-rHuMGDF. A single patient with sarcoma developed an antibody against full-length TPO. However, this reaction was considered transient and not clinically relevant. ${ }^{72}$ Notably, this response was never seen immediately, and was always mediated by the $\operatorname{IgG}_{4}$ sub-type. ${ }^{87}$ Even though $\mathrm{IgG}_{4}$ only accounts for approximately $5 \%$ of the total $\mathrm{IgG}$ concentration, it is notable that this immunoglobulin isotype causes other autoimmune responses, including antifactor VIII antibodies seen in congenital and acquired hemophilia. ${ }^{89}$ Typically, this response arises from B-cells arising from $\mathrm{T}$ helper cells $\mathrm{T}_{\mathrm{h}} 2$ stimulation. ${ }^{90}$ Nevertheless, the development of autoantibodies against TPO effectively halted any further clinical development of the recombinant TPO agents.

\section{Emergence of TPO mimetics}

The observation that the recombinant TPO's could elicit the development of an immune response against exogenous, as well as endogenous TPO provoked the development of alternative TPO mimetics. This led to rationally designed TPO receptor (TPOr) agonists, which were developed because they were predicted to have a very low potential for generating an antibody response. These novel compounds have no homology to endogenous TPO, yet are able to activate the TPOr. Progress in this area represents the most exciting and innovative area of ITP and thrombocytopenia treatment in decades, and has the potential for changing the landscape of therapeutics for thrombocytopenia.

Prior to the emergence of neutralizing antibodies with the initial trials of the recombinant TPO compounds, pioneering research into alternative TPOr agonists were performed with phage display libraries. Screening this library revealed a 14-amino acid peptide that bound to the TPOr, yet lacked homology to TPO. ${ }^{91}$ Furthermore, when the peptide was dimerized, it was able to bind to the TPOr with the same affinity as TPO, yet it was one tenth the size. The dimerized peptide had the same effect as rhTPO in producing an increase in megakaryocyte colony numbers. ${ }^{91}$ The dimerized peptide was modified by derivatizing the $\mathrm{N}$-termini of both ends of the dimer, and then pegylated to increase half-life. ${ }^{92}$ While this compound (now known as GW395058) is not undergoing clinical trials in humans, it opened the door for other TPO mimetics that do not share homology with TPO, thereby decreasing the risk of eliciting an antibody response.

Drawing upon alternative ways to bind to and activate the TPOr, a murine monoclonal antibody (named BAH-1 $)^{93}$ possessing agonist activity towards TPOr was generated. In vitro studies showed that $\mathrm{BAH}-1$ bound to megakaryocyte progenitors, and stimulated their growth and maturation. The fully intact antibody is able to stimulate the TPOr, while fragment antigen-binding ( $\mathrm{Fab}$ ) fragments of BAH-1 can not, suggesting that BAH-1, like native TPO BAH-1 functions by inducing TPOr dimerization upon ligand binding. While BAH-1 was able to increase megakaryocyte progenitors, the use of BAH-1 in mice that were myelosuppressed was only modestly successful. ${ }^{93}$ Although this compound did not undergo further clinical testing, it did provide the "proof of principle" for further novel compounds.

\section{TPO mimetics used in humans}

Romiplostim (Nplate ${ }^{\mathrm{TM}}$, Amgen, Thousand Oaks, CA) is the first TPOr agonist to be approved by the US Food and Drug Administration (FDA). Approved for use in humans on August 22nd, 2008, romiplostim was originally studied as the Amgen megakaryopoiesis protein-531 (AMG-531). It was granted orphaned drug status in 2003, and fast-tracked by the FDA in $2004 .^{94}$ Romiplostim is composed of four peptides 
that are capable of binding to the TPOr, and are fused to an fragment crystallizable $(\mathrm{Fc})$ carrier domain. This unique drug structure known as a "peptibody" is the first type of compound of this drug class to be used in humans ${ }^{95}$ (Figure 1). Since the TPOr-binding regions of romiplostin do not share sequence homology with TPO, an immune response against romiplostin should not cross react with native TPO. The Fc domain of romiplostim binds to the FcRn salvage receptor, which then undergoes endothelial recirculation, significantly prolonging the life of romiplostim in plasma. ${ }^{96}$ In addition to increasing platelet counts, romiplostim augments the growth of megakaryocyte colony-forming units, and megakaryocyte maturation. ${ }^{97}$

\section{Phase I/II studies}

Romiplostim underwent two phase I/II open label dose escalation trials in study subjects with chronic ITP. ${ }^{98,99}$ In this initial study, sixteen subjects with ITP were given 30 , 100,300 , or $500 \mu \mathrm{g}$ of romiplotsim, and platelet counts were measured regularly. A study subject given the highest dose of $500 \mu \mathrm{g}$ achieved a platelet count of $1,062 / \mu 1$. This patient was withdrawn from the study, and this dose was discontinued. Only one other patient had an unacceptably high platelet count when administered the $300 \mu \mathrm{g}$ dose. Of the remaining fourteen subjects, twelve had increases in platelet counts that occurred within ten days of dosing, with a mean increase of $>20$ in platelet count above baseline. Adverse events were minimal, and were limited to headache and rebound thrombocytopenia when the study drug was discontinued. Analysis of the amount of romiplostim used led to a weight based conversion, where platelet responses were seen at doses $>1 \mu \mathrm{g} / \mathrm{kg} .{ }^{98}$

A follow-up phase I/II study involved nine US centers and 24 subjects with chronic ITP. Study participants were

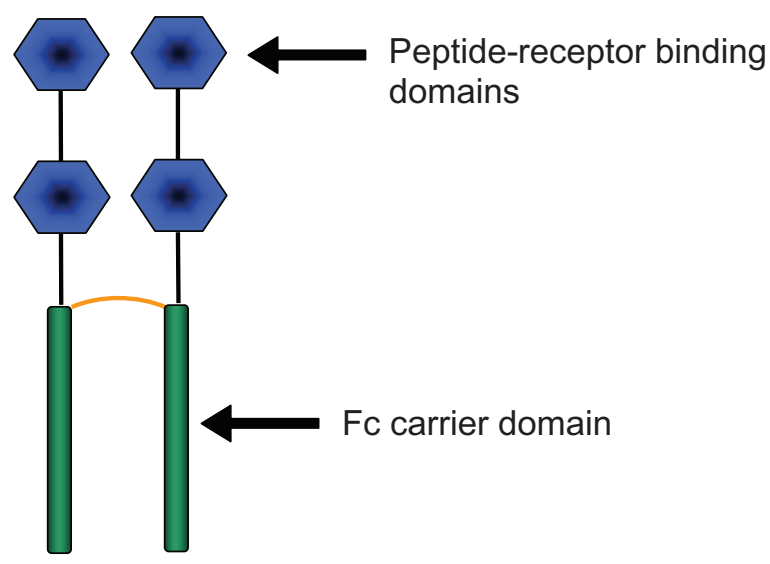

Figure I Structure of romiplostim. treated with a weight based schedule of $0.2,0.5,1,3,6$, and $10 \mu \mathrm{g} / \mathrm{kg}$. Doses of romiplostim $<1 \mu \mathrm{g} / \mathrm{kg}$ were found to be ineffective in raising the platelet count, whereas higher doses (3-10 $\mu \mathrm{g} / \mathrm{kg}$ ) were more effective. Responses were generally seen in about a week, with peak responses occurring 10-14 days afterwards. ${ }^{99}$

The phase II portion was a double-blind, placebocontrolled trial, with four subjects in a placebo group and 17 in the treatment arm receiving 1,3 , or $6 \mu \mathrm{g} / \mathrm{kg}$ of romiplostim. ${ }^{99}$ After three weeks, the $6 \mu \mathrm{g} / \mathrm{kg}$ dose was eliminated after a study participant developed a platelet count of 520. However, weekly subcutaneous administration of 1 and $3 \mu \mathrm{g} / \mathrm{kg}$ increased the platelet counts in a majority of patients, as twelve out of sixteen patients had increases in their platelet counts. The median time for response was 18 and 19 days, for 1 and $3 \mu \mathrm{g} / \mathrm{kg}$, respectively. As was observed in the initial studies, adverse events were mild in severity. Ecchymoses and headache remain common findings, and two study subjects had worsening thrombocytopenia after the cessation of romiplostim..$^{99}$

\section{Phase III trials}

Phase III trials of romiplostim enrolled patients with ITP, who might, or might not have had a splenectomy. ${ }^{100}$ Two simultaneous trials were conducted in a double-blind, placebo controlled, and international multicenter trial. Patients were enrolled 2:1 for romiplostim vs placebo. Sixty-three study participants were enrolled in the splenectomy group, and 62 in the nonsplenectomy group. Patients were dosed weekly with romiplostim or placebo for 24 weeks, with dose adjustments made to maintain a platelet count of 50,000-200,000. While concurrent use of oral immunosuppressant agents and rescue medications was allowed, study subjects were not enrolled if recently treated with IVIg or anti-D, alkylating agents, rituximab, or other modalities. The primary outcome was a "durable platelet response", which was defined as a weekly platelet count of $>50$ during six or more weeks of the last eight weeks of treatment. A "transient platelet response" was defined as "four or more weekly platelet responses without a durable platelet response from weeks 2 to $25 .{ }^{100}$

In addition to analyzing the effects of romiplostim on ITP, researchers were able to show that treatment with it was capable of improving the quality of life (QoL) of patients with ITP. ${ }^{101}$ Using the same population in the phase III study, it was observed that patients, who had undergone splenectomy, had lower baseline scores when compared to nonsplenectomized patients. While this may be attributed to a more severe or chronic form of the disease, the splenectomized patients 
had a greater improvement in their QoL scores, than patients with intact spleens, or patients on placebo. Nonsplenectomized patients had a higher QoL in the activity scales when compared to patients on placebo. ${ }^{101}$

The results from a single-arm, long-term safety and efficacy study, involving 142 study subjects, some followed for as long as three years, has been reported, and has undergone peer review. ${ }^{102}$ The majority of treated subjects $(87 \%)$ were able to mount a platelet response without developing resistance to the effects of romiplostim. Furthermore, when compared to the phase III results, subjects followed in this long-term observational study had a lower number of bleeding episodes. Those that had hemorrhagic symptoms, did so only at platelet counts of $<30 \times 10^{9} / \mathrm{L}$. This lends additional support to the observation that bleeding in ITP occurs at lower values. An added benefit that was noted during this study was that $84 \%$ of the subjects treated with romiplostim were able to discontinue their concurrent ITP treatments. While increasing the platelet count, it must be noted that romiplostim is ineffective in altering the pathophysiology of ITP, since platelet counts return to baseline following its discontinuation. ${ }^{102}$

\section{Adverse effects of romiplostim}

Throughout the studies evaluating the safety and efficacy of romiplostim, to date, no antibodies directed against TPO have been detected, although one subject had a transient antibody response to romiplostim. ${ }^{102}$ As stated above, the most commonly reported adverse effects have been bruising and mild to moderate headaches.

The most significant known adverse effect of romiplostim is the potential for increasing deposits of reticulin in the bone marrow. Rodents treated with PEG-rHuMGDF were found to have increased marrow reticulin. In these animals, the fibrosis is mediated by transforming growth factor- $\beta 1$ (TGF- $\beta 1) .{ }^{103-105}$ Additional support for the role of TGF- $\beta 1$ comes from experiments in mice that are engineered to overexpress TPO. When these mice are lethally irradiated and then rescued with wild-type hematopoietic stem cells (HSC) or HSC that are engineered to be TGF- $\beta 1$ null (TGF- $\beta 1^{-/-}$) it was observed that the TGF- $\beta 1^{-/-}$were protected against the development of reticulin deposits as compared to their wild-type littermates. ${ }^{106}$ A similar effect has been observed in human subjects receiving romiplostim, although the significance of this increase in reticulin is unknown. This was first observed in two study subjects during the phase I/II studies, ${ }^{99}$ and subsequently monitored in the phase III studies. ${ }^{100}$ Eight study subjects were found to have an increase in bone marrow reticulin in the long-term safety study. ${ }^{102}$ In all, 10 out of 271 ITP study subjects have developed increased reticulin. However, it has been observed that cessation of therapy leads to a normalization of reticulin level. ${ }^{107}$ The participants who developed an increase in bone marrow reticulin were found to have either undergone splenectomy, required extensive treatment for ITP, received high doses of romiplostim, or had a minimal response to the treatment.

A bone marrow biopsy is not required prior to initiation of romiplostim. Instead, careful analysis of the peripheral blood smear before and during treatment is recommended. If the peripheral blood smear shows signs of myelofibrosis (such as nucleated red cells, dacrocytes) or other cytopenias develop, romiplostim should be stopped and a bone marrow biopsy, with attention to reticulin staining, is strongly encouraged. ${ }^{108}$

Another risk associated with romiplostim is an exacerbation of thrombocytopenia after it is discontinued. Four study participants in the phase I/II study had a transient worsening of their baseline thrombocytopenia after romiplostim was discontinued, leading one to experience vaginal bleeding. ${ }^{99}$ Recommendations are to monitor complete blood counts after stopping romiplostim and to consider alternative therapies if clinically indicated. ${ }^{108}$

With the increase in platelet counts, theoretical concerns have existed over an increased risk of thrombosis. While there was no noticeable effect in platelet aggregometry studies performed in healthy Japanese males, ${ }^{109}$ thrombotic and thromboembolic events have been observed in the clinical trials evaluating romiplostim. A total of 12 events were observed in seven patients, and included deep vein thrombosis, myocardial infarction, and transient ischemic attack. ${ }^{102}$ However, the study investigators felt that this rate of thrombotic events was no different when compared to the natural history of thrombosis in ITP patients.

\section{Eltrombopag}

Like romiplostim, eltrombopag (Promacta ${ }^{\mathrm{TM}}$; GlaxoSmithKline, Philadelphia, PA) is another TPOr agonist that has been FDA-approved. However, it is unique in that it is a nonpeptide small molecule that binds to the TPOr (Figure 2). Using a high-throughput cell based assay, several hundred thousand nonpeptide compounds were tested from chemical compound libraries. The study identified hydrazinonaphthalene and azonaphthalene compounds as potential nonpeptide activators of the TPOr. ${ }^{110}$ From this initial screen, these compounds were further modified for increased bioavailability, and improved pharmacokinetics. Eventually, the test molecule 


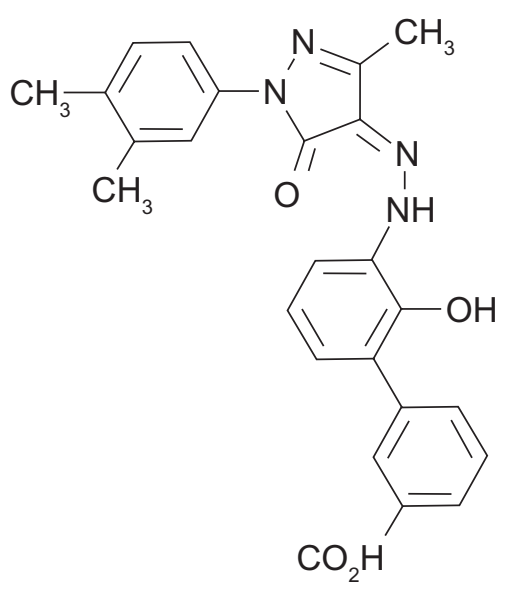

Figure 2 Chemical structure of eltrombopag.

SB-497115 ${ }^{111}$ (now termed eltrombopag), was designed, and had the advantage of being the first orally bioavailable nonpeptide-based TPOr agonist. Preclinical data on the biologic characteristics of eltrombopag shows that it is able to bind to the TPOr in a noncompetitive fashion with endogenous TPO. Using thymidine incorporation assays, eltrombopag is additive to the effects of TPO, ultimately reaching a plateau in their combined effects. Furthermore, using cell based assays, eltrombopag binds almost exclusively to the TPOr, without binding to the Epo, G-CSF, IFN- $\alpha$, IFN- $\gamma$, or IL3 receptors. ${ }^{112,113}$ When eltrombopag binds to the TPOr, the JAK/STAT5 pathway is activated, leading to MAPK stimulation. ${ }^{110,113}$ These intracellular events help to explain how eltrombopag leads to the proliferation and differentiation of megakaryocytes, ultimately causing the observed increase in platelet counts. The effects of eltrombopag appear to be limited to platelet production, as in vitro assays show that it does not induce or inhibit platelet aggregation, whereas, rhTPO can enhance ADP-mediated platelet aggregation. ${ }^{114}$

\section{Phase I studies}

Clinical trials with eltrombopag were initiated in a phase I study with 73 participants who were given placebo and eltrombopag at doses from 5-75 mg daily. ${ }^{115}$ It was observed that doses greater than $30 \mathrm{mg}$ administered for ten days produced measurable increases in platelet counts fourteen to 16 days later, with higher response rates observed at the 50 and $75 \mathrm{mg}$ doses. As could be expected, withdrawal of eltrombopag caused the platelet counts to return to baseline levels. In this phase I study, there was no difference in the incidence of adverse events between the eltrombopag or placebo groups, and platelet aggregation profiles remained unchanged. ${ }^{115}$
Pharmacokinetic studies performed during the phase I studies indicated that calcium salts, particularly in the form of antacids, decreased the gastrointestinal absorption of eltrombopag. This observation ultimately led to the recommendation that a four-hour separation occur between the ingestion of the medication and other compounds known to contain metal cations, particularly calcium. ${ }^{116}$

\section{Phase II studies}

Eltrombopag was next evaluated in two distinct patient populations with thrombocytopenia: 1) patients with ITP $^{117}$ or 2) thrombocytopenic patients with cirrhosis from hepatitis $\mathrm{C}$, who were to be treated with ribavirin and pegylated INF. ${ }^{118}$ A phase II study with 117 ITP subjects was performed where subjects were treated for six weeks with placebo, 30,50 , or $75 \mathrm{mg}$ daily, and were stratified according to use of concurrent ITP medications, splenectomy, and platelet counts of greater than $15,000 / \mu 1$. The primary endpoint was set to be a platelet count $>50,000 / \mu 1$, and the secondary endpoints focused on safety, QoL, and incidence of bleeding symptoms. A greater percentage of study participants responded to the higher doses, with $81 \%, 70 \%, 28 \%$, and $11 \%$ reaching the primary endpoint when treated with $75 \mathrm{mg}, 50 \mathrm{mg}, 30 \mathrm{mg}$ of eltrombopag, or placebo, respectively. No differences were noted between the responses in patients who did, or did not have a splenectomy, or based on either age or race. Investigators noted that study subjects treated at the 75 and $50 \mathrm{mg}$ doses had decreased bleeding episodes, implying adequate hemostatic capability of the increased platelet count. Adverse effects were similar in all study groups, including the placebo arm, with the most common reported symptom being headache. ${ }^{117}$

A second phase II study was performed in patients with thrombocytopenia from liver disease and concurrent hepatitis C infection to assess if eltrombopag could increase the platelet count to allow antiviral therapy with ribavirin and INF. ${ }^{118}$ Again, placebo, $30 \mathrm{mg}, 50 \mathrm{mg}$, or $75 \mathrm{mg}$ daily for four weeks was used in adult patients with baseline platelet counts of $20,000-70,000 / \mu 1$, and were stratified according to baseline platelet counts of $20,000-50,000 / \mu 1$ or $50,000-70,000 / \mu 1$. In this international, multi-center, double-blind, randomized, placebo-controlled trial, subjects were monitored for responses to eltrombopag, and if successful, they underwent treatment with ribavirin and IFN, while continuing their allocated treatment. The majority of subjects responded to eltrombopag ( $71 \%-91 \%)$, and $36 \%-65 \%$ were able to complete 12 weeks of hepatitis $\mathrm{C}$ therapy. Even when platelet 
counts fell, presumably due to the antiviral treatment, the platelet counts still remained above baseline, allowing for the continuation of treatment. ${ }^{118}$ As with the ITP treatment study, ${ }^{117}$ headache was the most commonly reported side effect.

\section{Phase III studies}

One hundred and fourteen patients with ITP were enrolled into a double-blind, placebo-controlled study, using $50 \mathrm{mg}$ or $75 \mathrm{mg}$ of eltrombopag daily. ${ }^{119}$ They were stratified according to splenectomy status, need for concurrent ITP therapy, and a platelet count $>15,000 / \mu 1$. The primary endpoint of the study was to achieve a platelet count $>50,000 / \mu \mathrm{l}$ in six weeks, with secondary endpoints of platelet counts, proportion of patients with platelet counts $>50,000 / \mu 1$, bleeding symptoms, and safety, among others.

Patients who received eltrombopag had significantly greater odds of achieving a platelet response $>50,000 / \mu 1$ than did the placebo group. No impact of concurrent ITP treatment or effect of splenectomy was noted. Bleeding symptoms were lower in the treatment than in the placebo arm, implying that the increased platelets were sufficient in number and quality for hemostasis.

\section{Side effects of eltrombopag}

As with romiplostim, the side effects of eltrombopag appear to be mild to moderate, and are limited to such symptoms such as headache, dry mouth, nausea, myalgia, and/or arthralgia. ${ }^{117-}$ 119 To date, no immune response against eltrombopag or to TPO has been observed in study participants.

An effect upon liver function, as evidence by a transaminitis, led to a "black-box" warning following FDA approval. Observed in three study subjects in the phase II trial, ${ }^{117}$ and then reported in a total of six patients in the phase III trial, ${ }^{119}$ the degree transaminitis was at least twice the upper limit of normal, causing the withdrawal of one study participant. As a result, it is recommended that alanine aminotransferase, aspartate aminotransferase, and bilirubin levels be checked at baseline, bi-monthly as dose adjustments are made, and then monthly once the patient is on a stable dose. ${ }^{120}$ Increased levels should be re-checked in 3-5 days and monitored for resolution, stabilization, or increase. If levels increase $>3 \times$ the upper limit of normal, are progressive, persist longer than 4 weeks, are accompanied by an increase in direct bilirubin, or associated with other clinical symptoms of hepatic injury, then eltrombopag should be discontinued. ${ }^{120}$

Use of eltrombopag may also be associated with the development or progression of cataracts. One study subject in the placebo arm and two in the treatment arm of the phase III study had progression of their existing cataracts. The study investigators revealed that these three patients had also been treated with corticosteroids. ${ }^{119}$ It is recommended that an ophthalmologic exam should be performed during initiation of therapy and that treated patients be monitored regularly. ${ }^{120}$

After eltrombopag is discontinued, the platelet count is expected to return to baseline. As was noted with romiplostim, a "rebound thrombocytopenia" may occur, predisposing the patient towards hemorrhagic symptoms. Two study subjects in the phase III study suffered bleeding episodes when their platelet count fell to $<10,000 / \mu 1$, which was lower than their baseline level. ${ }^{119}$

Another risk associated with the use of eltrombopag is thrombosis. Physicians are cautioned against using doses that excessively raise the platelet count. A total of 11 thromboembolic events were noted in the clinical trials of eltrombopag, ${ }^{121}$ leading the FDA to caution the use of this mediation in patients with known risk factors for venous thromboembolism. ${ }^{120}$

As was observed with romiplostim, an increase in the formation of bone marrow reticulin was noted. In all, seven of the 19 study subjects in the extension study were noted to have bone marrow reticulin formation, although two of these subjects had reticulin deposition at baseline. ${ }^{121}$ Physicians are encouraged to evaluate the peripheral blood smear, with attention to erythrocyte morphology. After a stable dose has been achieved, regular examination of the peripheral smear and complete blood count is recommended. Any cytopenia or suggestion of morphologic abnormality, eltrombopag should be discontinued and a bone marrow biopsy with reticulin staining is recommended. ${ }^{120}$

\section{Other compounds}

While romiplostim and eltrombopag are the only FDAapproved TPO mimetics, there are a number of other compounds that have been investigated in humans. While limited to reports in abstract form, they represent possible "back-ups" to those that are currently available. These potential agents include SB-559448, an oral nonpeptide TPOr agonist that has undergone phase I study in humans; ${ }^{122}$ AKR-501 which has also undergone a phase I study and is found to be effective in raising platelet counts in healthy volunteers. ${ }^{123}$

\section{TPO mimetics in development}

\section{Minibodies}

Alternative mechanisms of TPOr activation include the creation of a "minibody," which is derived from an anti-Mpl 
antibody. ${ }^{124}$ Upon binding to the $\mathrm{Mpl}$ receptor, the minibody causes dimerization of the receptor, leading to its activation. Two such novel molecules have been described, VB22B $\mathrm{sc}(\mathrm{Fv}) 2$ and TA136 sc(Fv)2. Both agents were effective in increasing platelet counts in vitro, and TA136 sc(Fv)2 shows promise in being the first thrombopoietic agent that may be effective in activating the dysfunctional receptor in congenital amegakaryocytic thrombocytopenia. ${ }^{124}$

\section{Fab 59}

As mentioned above, screening of peptide libraries led to the discovery of amino acid sequences that could bind to, and activate TPOr. ${ }^{91}$ One such peptide, AF12505, was inserted into the heavy chain $(\mathrm{HC})$ complementarity determining region (CDR) of the human tetanus-toxoid antibody. ${ }^{125}$ This configuration yielded a molecule that was just as effective as rhTPO in stimulating the TPOr, and had a much longer in vivo half-life than the dimerized peptide, AF13948. Researchers have posited that this design might have advantages over a peptibody design because the Fc region is eliminated, thereby theoretically eliminating inadvertent immune stimulation. ${ }^{125}$

\section{NIP-004}

NIP-004 is another hydrazine compound identified after screening more than 50,000 compounds in cell proliferation assays. ${ }^{126}$ Analogous to eltrombopag, NIP-004 is species selective, and therefore will only activate the human TPOr. Structure-function studies identified that NIP-004-binding was dependent upon a histidine at position 499 of human Mpl, and this residue confers the species specificity. ${ }^{126}$ Preclinical studies suggest that this compound will stimulate megakaryocyte growth similar to other TPOr agonists.

\section{Conclusion}

After many decades of basic science and clinical research, significant strides have been made in understanding the pathophysiology and treatment of thrombocytopenia. This deeper understanding of the mechanisms causing immune mediated thrombocytopenia has opened new avenues to help ameliorate and treat the symptoms of thrombocytopenia.

The use of nonspecific immune modulators and immunosuppressive agents to treat thrombocytopenia has given rise to targeted agents, particularly those that activate the TOPr. While initial trials showed great promise for the use of PEG-rHuMGDF and rhTPO in a variety of disease states and clinical applications, the development of auto-antibodies against the recombinant TPO molecules halted further development. This provided the impetus for the generation of novel compounds to treat thrombocytopenia.

These novel agents include peptide-based TPOr agonists such as romiplostim and nonpeptide compounds such as eltrombopag, which activate the TPO receptor. The potential use of all these agents represents some of the most significant breakthroughs in the treatment of thrombocytopenia in decades. Who should receive these new drugs, and how they should be given are areas of current investigation.

However, enthusiasm for these new medications need to be tempered with uncertainty; not for their efficacy in increasing the platelet count, but for concern of their safety. Eltrombopag and romiplostim have not been followed prospectively for a significant length of time, particularly in the nonstudy patient. The true incidence and impact of bone marrow fibrosis with the use of TPO mimetics remains unknown and potentially serious. Likewise, thrombotic complications may increase if use of TPO mimetics is broadened to the general population. Long-term data remains to be collected, detailing the clinical outcomes of patients with chronic use of TPO mimetics.

The use of TPO mimetics will hopefully mean a safer and more effective alternative for the treatment of ITP. However, clinical questions remain for the practitioner as to the proper use of the TPO mimetics in an acute case of ITP or in one who has failed the first round of steroid use. Could TPO mimetics be used instead of steroids in a patient with diabetes? What is the role of splenectomy now in ITP? How does use the of TPO mimetics change the course of ITP? In addition, it is very likely that the cost of TPO mimetics over extended periods of time will raise additional concerns, particularly if less expensive alternatives exist. Despite these inevitable issues, physicians who treat thrombocytopenia, and their patients, remain cautiously optimistic about the use of TPO mimetics in the patient with chronic refractory ITP.

\section{Disclosure}

This work was supported by the Duke-UNC Clinical Hematology Research Career Development program (5K12HL-08709-04). The authors report no conflicts of interest in this work.

\section{References}

1. George JN, Woolf SH, Raskob GE, et al. Idiopathic thrombocytopenic purpura: a practice guideline developed by explicit methods for the American Society of Hematology. Blood. 1996;88(1):3-40.

2. British Committee for Standards in Haematology General Haematology Task Force. Guidelines for the investigation and management of idiopathic thrombocytopenic purpura in adults, children and in pregnancy. Br J Haematol. 2003;120(4):574-596. 
3. Cines DB, Blanchette VS. Immune thrombocytopenic purpura. $N E n g l$ J Med. 2002;346(13):995-1008.

4. Whipple A. Splenectomy as a therapeutic measure in thrombocytopenic purpura hæmorrhagica. Surg Gynecol Obstetr. 1926;42:329-341.

5. Meyers MM S, Bethell FH. Administration of ACTH in hypersplenic syndromes. J Lab Clin Med. 1950;36(6):965-966.

6. Bethell FM MC, Miller S, Bullock WH. Effects of ACTH and cortisone on idiopathic thrombocytopenic purpura. Trans Assoc Am Physicians. 1951;64:199-203.

7. Verlin M, Laros RK Jr, Penner JA. Treatment of refractory thrombocytopenic purpura with cyclophosphamine. Am J Hematol. 1976;1(1): $97-104$.

8. Sussman LN. Azathioprine in refractory idiopathic thrombocytopenic purpura. JAMA. 1967;202(4):259-263.

9. Proctor SJ, Jackson G, Carey P, Stark A. Short-course alpha-interferon therapy in severe unresponsive immune thrombocytopenic purpura. Lancet. 1988;1(8591):947.

10. Kelsey PR, Schofield KP, Geary CG. Refractory idiopathic thrombocytopenic purpura (ITP) treated with cyclosporine. Br J Haematol. 1985;60(1):197-198.

11. Howard J, Hoffbrand AV, Prentice HG, Mehta A. Mycophenolate mofetil for the treatment of refractory auto-immune haemolytic anaemia and auto-immune thrombocytopenia purpura. Br J Haematol. 2002;117(3):712-715.

12. Godeau B, Oksenhendler E, Bierling P. Dapsone for autoimmune thrombocytopenic purpura. Am J Hematol. 1993;44(1):70-72.

13. McMinn JR Jr, Cohen S, Moore J, et al. Complete recovery from refractory immune thrombocytopenic purpura in three patients treated with etanercept. Am J Hematol. 2003;73(2):135-140.

14. Ahn YS, Harrington WJ, Simon SR, Mylvaganam R, Pall LM, So AG. Danazol for the treatment of idiopathic thrombocytopenic purpura. N Engl J Med. 1983;308(23):1396-1399.

15. George JN. Management of patients with refractory immune thrombocytopenic purpura. J Thromb Haemost. 2006;4(8):1664-1672.

16. Portielje JE, Westendorp RG, Kluin-Nelemans HC, Brand A. Morbidity and mortality in adults with idiopathic thrombocytopenic purpura. Blood. 2001;97(9):2549-2554.

17. George JN, Vesely SK. Immune thrombocytopenic purpura-let the treatment fit the patient. N Engl J Med. 2003;349(9):903-905.

18. Dameshek W, Miller EB. The Megakaryocytes in idiopathic thrombocytopenic purpura, a form of hypersplenism. Blood. 1946;1(1)27-51.

19. Stoll D, Cines DB, Aster RH, Murphy S. Platelet kinetics in patients with idiopathic thrombocytopenic purpura and moderate thrombocytopenia. Blood. 1985;65(3):584-588.

20. Heyns Adu P, Badenhorst PN, Lotter MG, Pieters H, Wessels P, Kotze HF. Platelet turnover and kinetics in immune thrombocytopenic purpura: results with autologous $111 \mathrm{In}$-labeled platelets and homologous $51 \mathrm{Cr}$ labeled platelets differ. Blood. 1986;67(1):86-92.

21. Ballem PJ, Segal GM, Stratton JR, Gernsheimer T, Adamson JW, Slichter SJ. Mechanisms of thrombocytopenia in chronic autoimmune thrombocytopenic purpura. Evidence of both impaired platelet production and increased platelet clearance. J Clin Invest. 1987;80(1):33-40.

22. Gernsheimer T, Stratton J, Ballem PJ, Slichter SJ. Mechanisms of response to treatment in autoimmune thrombocytopenic purpura. N Engl J Med. 1989;320(15):974-980.

23. Keleman EC I, Tanos B. Demonstration and some properties of human thrombopoietin in thrombocythaemic sera. Acta Haem. 1958;20(6):350-355.

24. De Gabriele G, Penington DG. Physiology of the regulation of platelet production. Br J Haematol. 1967;13(2):202-209.

25. Wendling F, Varlet P, Charon M, Tambourin P. MPLV: a retrovirus complex inducing an acute myeloproliferative leukemic disorder in adult mice. Virology. 1986;149(2):242-246.

26. Le Coniat M, Souyri M, Vigon I, Wendling F, Tambourin P, Berger R. The human homolog of the myeloproliferative virus maps to chromosome band 1p34. Hum Genet. 1989;83(2):194-196.
27. Souyri M, Vigon I, Penciolelli JF, Heard JM, Tambourin P, Wendling F. A putative truncated cytokine receptor gene transduced by the myeloproliferative leukemia virus immortalizes hematopoietic progenitors. Cell. 1990;63(6):1137-1147.

28. Vigon I, Mornon JP, Cocault L, et al. Molecular cloning and characterization of MPL, the human homolog of the $v-m p l$ oncogene: identification of a member of the hematopoietic growth factor receptor superfamily. Proc Natl Acad Sci U S A. 1992;89(12): $5640-5644$.

29. Methia N, Louache F, Vainchenker W, Wendling F. Oligodeoxynucleotides antisense to the proto-oncogene $c-m p l$ specifically inhibit in vitro megakaryocytopoiesis. Blood. 1993;82(5):1395-1401.

30. Gurney AL, Carver-Moore K, de Sauvage FJ, Moore MW. Thrombocytopenia in c-mpl-deficient mice. Science. 1994;265(5177): $1445-1447$.

31. Alexander WS, Roberts AW, Nicola NA, Li R, Metcalf D. Deficiencies in progenitor cells of multiple hematopoietic lineages and defective megakaryocytopoiesis in mice lacking the thrombopoietic receptor c-Mpl. Blood. 1996;87(6):2162-2170.

32. Kimura S, Roberts AW, Metcalf D, Alexander WS. Hematopoietic stem cell deficiencies in mice lacking $c-M p l$, the receptor for thrombopoietin. Proc Natl Acad Sci U S A. 1998;95(3):1195-1200.

33. de Sauvage FJ, Hass PE, Spencer SD, et al. Stimulation of megakaryocytopoiesis and thrombopoiesis by the $\mathrm{c}-\mathrm{Mpl}$ ligand. Nature. 1994;369(6481):533-538.

34. Lok S, Kaushansky K, Holly RD, et al. Cloning and expression of murine thrombopoietin cDNA and stimulation of platelet production in vivo. Nature. 1994;369(6481):565-568.

35. Kaushansky K, Lok S, Holly RD, et al. Promotion of megakaryocyte progenitor expansion and differentiation by the $\mathrm{c}-\mathrm{Mpl}$ ligand thrombopoietin. Nature. 1994;369(6481):568-571.

36. Bartley TD, Bogenberger J, Hunt $\mathrm{P}$, et al. Identification and cloning of a megakaryocyte growth and development factor that is a ligand for the cytokine receptor Mpl. Cell. 1994;77(7):1117-1124.

37. Wendling F, Maraskovsky E, Debili N, et al. $c-M p l$ ligand is a humoral regulator of megakaryocytopoiesis. Nature. 1994;369(6481): 571-574.

38. Sohma Y, Akahori H, Seki N, et al. Molecular cloning and chromosomal localization of the human thrombopoietin gene. FEBS Let. 1994;353(1):57-61.

39. Kaushansky K. The molecular mechanisms that control thrombopoiesis. J Clin Invest. 2005;115(12):3339-3347.

40. Broudy VC, Lin NL, Kaushansky K. Thrombopoietin (c-mpl ligand) acts synergistically with erythropoietin, stem cell factor, and interleukin-11 to enhance murine megakaryocyte colony growth and increases megakaryocyte ploidy in vitro. Blood. 1995;85(7): 1719-1726.

41. van Willigen G, Gorter G, Akkerman JW. Thrombopoietin increases platelet sensitivity to alpha-thrombin via activation of the ERK2-cPLA2 pathway. Thromb Haemost. 2000;83(4):610-616.

42. Akkerman JW. Thrombopoietin and platelet function. Semin Thromb Hemost. 2006;32(3):295-304.

43. Kaushansky K. Thrombopoietin: a tool for understanding thrombopoiesis. J Thromb Haemost. 2003;1(7):1587-1592.

44. Alexander WS, Metcalf D, Dunn AR. Point mutations within a dimer interface homology domain of $\mathrm{c}-\mathrm{Mpl}$ induce constitutive receptor activity and tumorigenicity. EMBO J, 1995;14(22):5569-5578.

45. Miyakawa Y, Oda A, Druker BJ, et al. Recombinant thrombopoietin induces rapid protein tyrosine phosphorylation of Janus kinase 2 and Shc in human blood platelets. Blood. 1995;86(1):23-27.

46. Drachman JG, Griffin JD, Kaushansky K. The c-Mpl ligand (thrombopoietin) stimulates tyrosine phosphorylation of Jak2, Shc, and c-Mpl. J Biol Chem. 1995;270(10):4979-4982.

47. Miyakawa Y, Drachman JG, Gallis B, Kaushansky A, Kaushansky K. A structure-function analysis of serine/threonine phosphorylation of the thrombopoietin receptor, c-Mpl. J Biol Chem. 2000; 275(41):32214-32219. 
48. Miyakawa Y, Oda A, Druker BJ, et al. Thrombopoietin induces tyrosine phosphorylation of Stat3 and Stat5 in human blood platelets. Blood. 1996;87(2):439-446.

49. Gurney AL, Wong SC, Henzel WJ, de Sauvage FJ. Distinct regions of $c-M p l$ cytoplasmic domain are coupled to the JAK-STAT signal transduction pathway and Shc phosphorylation. Proc Natl Acad Sci U S A. 1995;92(12):5292-5296.

50. Nagata $Y$, Todokoro $\mathrm{K}$. Thrombopoietin induces activation of at least two distinct signaling pathways. FEBS Lett. 1995;377(3):497-501.

51. Kaushansky K, Drachman JG. The molecular and cellular biology of thrombopoietin: the primary regulator of platelet production. Oncogene. 2002;21(21):3359-3367.

52. Yamada M, Komatsu N, Okada K, Kato T, Miyazaki H, Miura Y. Thrombopoietin induces tyrosine phosphorylation and activation of mitogen-activated protein kinases in a human thrombopoietin-dependent cell line. Biochem Biophys Res Commun. 1995;217(1):230-237.

53. Rojnuckarin P, Drachman JG, Kaushansky K. Thrombopoietin-induced activation of the mitogen-activated protein kinase (MAPK) pathway in normal megakaryocytes: role in endomitosis. Blood. 1999;94(4) 1273-1282.

54. Hunt P, Li YS, Nichol JL, et al. Purification and biologic characterization of plasma-derived megakaryocyte growth and development factor. Blood. 1995;86(2):540-547.

55. Hirayama Y, Sakamaki S, Matsunaga T, et al. Concentrations of thrombopoietin in bone marrow in normal subjects and in patients with idiopathic thrombocytopenic purpura, aplastic anemia, and essential thrombocythemia correlate with its mRNA expression of bone marrow stromal cells. Blood. 1998;92(1):46-52.

56. Kosugi S, Kurata Y, Tomiyama Y, et al. Circulating thrombopoietin level in chronic immune thrombocytopenic purpura. Br J Haematol. 1996;93(3):704-706.

57. Tahara T, Usuki K, Sato H, et al. A sensitive sandwich ELISA for measuring thrombopoietin in human serum: serum thrombopoietin levels in healthy volunteers and in patients with haemopoietic disorders. $\mathrm{Br} J$ Haematol. 1996;93(4):783-788.

58. Emmons RV, Reid DM, Cohen RL, et al. Human thrombopoietin levels are high when thrombocytopenia is due to megakaryocyte deficiency and low when due to increased platelet destruction. Blood. 1996;87(10):4068-4071.

59. Corazza F, Hermans C, D'Hondt S, et al. Circulating thrombopoietin as an in vivo growth factor for blast cells in acute myeloid leukemia. Blood. 2006;107(6):2525-2530.

60. De Gabriele G, Penington DG. Regulation of platelet production: "thrombopoietin". Br J Haematol. 1967;13(2):210-215.

61. Dahlen DD; Broudy VC; Drachman J. Internalization of the thrombopoietin receptor is regulated by 2 cytoplasmic motifs. Blood. 2003;103(1):102-108.

62. Kuter DJ, Rosenberg RD. The reciprocal relationship of thrombopoietin ( $c-M p l$ ligand) to changes in the platelet mass during busulfaninduced thrombocytopenia in the rabbit. Blood. 1995;85(10): 2720-2730.

63. Fielder PJ, Gurney AL, Stefanich E, et al. Regulation of thrombopoietin levels by $c$-mpl-mediated binding to platelets. Blood. 1996;87(6):2154-2161.

64. Nagasawa T, Hasegawa Y, Shimizu S, et al. Serum thrombopoietin level is mainly regulated by megakaryocyte mass rather than platelet mass in human subjects. Br J Haematol. 1998;101(2):242-244.

65. Terashi K, Oka M, Ohdo S, et al. Close association between clearance of recombinant human granulocyte colony-stimulating factor (G-CSF) and G-CSF receptor on neutrophils in cancer patients. Antimicrob Agents Chemother. 1999;43(1):21-24.

66. Harker LA. Therapeutic cytokine stimulation of thrombocytopoiesis. Transfus Sci. 1998;19(2):149-162.

67. Basser RL, Rasko JE, Clarke K, et al. Thrombopoietic effects of pegylated recombinant human megakaryocyte growth and development factor (PEG-rHuMGDF) in patients with advanced cancer. Lancet. 1996;348(9037):1279-1281.
68. Hokom MM, Lacey D, Kinstler OB, et al. Pegylated megakaryocyte growth and development factor abrogates the lethal thrombocytopenia associated with carboplatin and irradiation in mice. Blood. 1995;86(12):4486-4492.

69. Fanucchi M, Glaspy J, Crawford J, et al. Effects of polyethylene glycol-conjugated recombinant human megakaryocyte growth and development factor on platelet counts after chemotherapy for lung cancer. N Engl J Med. 1997:336(6):404-409.

70. Kuter DJ, Begley CG. Recombinant human thrombopoietin: basic biology and evaluation of clinical studies. Blood. 2002;100(10): 3457-3469.

71. Vadhan-Raj S, Verschraegen CF, Bueso-Ramos C, et al. Recombinant human thrombopoietin attenuates carboplatin-induced severe thrombocytopenia and the need for platelet transfusions in patients with gynecologic cancer. Ann Intern Med. 2000;132(5) 364-368.

72. Vadhan-Raj S, Murray LJ, Bueso-Ramos C, et al. Stimulation of megakaryocyte and platelet production by a single dose of recombinant human thrombopoietin in patients with cancer. Ann Intern Med. 1997;126(9):673-681.

73. Harker LA, Marzec UM, Novembre F, et al. Treatment of thrombocytopenia in chimpanzees infected with human immunodeficiency virus by pegylated recombinant human megakaryocyte growth and development factor. Blood. 1998;91(12):4427-4433.

74. Harker LACR, Marzec UM, Cherry JK, et al. Correction of thrombocytopenia and ineffective platelet production in patients infected with human immunodeficiency virus (HIV) by PEG-rHuMGDF therapy. Blood. 1998;92:707a.

75. Kuter DJ, Goodnough LT, Romo J, et al. Thrombopoietin therapy increases platelet yields in healthy platelet donors. Blood. 2001;98(5): $1339-1345$.

76. Goodnough LT, Kuter DJ, McCullough J, et al. Prophylactic platelet transfusions from healthy apheresis platelet donors undergoing treatment with thrombopoietin. Blood. 2001;98(5):1346-1351.

77. Nomura S, Dan K, Hotta T, Fujimura K, Ikeda Y. Effects of pegylated recombinant human megakaryocyte growth and development factor in patients with idiopathic thrombocytopenic purpura. Blood. 2002;100(2):728-730

78. Rice L, Nichol JL, McMillan R, Roskos LK, Bacile M. Cyclic immune thrombocytopenia responsive to thrombopoietic growth factor therapy. Am J Hematol. 2001;68(3):210-214.

79. Hua B, Zou N, Wang S, Zhu T, Zhao Y. Multiple cycles of recombinant human thrombopoietin therapy in a patient with chronic refractory idiopathic thrombocytopenic purpura. Blood Coagul Fibrinolysis. 2005;16(4):291-295.

80. Fontenay-Roupie M, Dupont JM, Picard F, et al. Analysis of megakaryocyte growth and development factor (thrombopoietin) effects on blast cell and megakaryocyte growth in myelodysplasia. Leuk Res. 1998;22(6):527-535.

81. Ferrajoli A, Talpaz M, Kurzrock R, et al. Thrombopoietin stimulates myelodysplastic syndrome granulocyte-macrophage and erythroid progenitor proliferation. Leuk Lymphoma. 1998;30(3-4): 279-292.

82. Kizaki M, Miyakawa Y, Ikeda Y. Long-term administration of pegylated recombinant human megakaryocyte growth and development factor dramatically improved cytopenias in a patient with myelodysplastic syndrome. Br J Haematol. 2003;122(5): 764-767.

83. Matsuda A, Misumi M, Ishikawa M, et al. Long-term improvement of anaemia in a patient with aplastic anaemia by short-term administration of pegylated recombinant human megakaryocyte growth and development factor. Br J Haematol. 2004;125(6):818-819.

84. Archimbaud E, Ottmann OG, Yin JA, et al. A randomized, doubleblind, placebo-controlled study with pegylated recombinant human megakaryocyte growth and development factor (PEG-rHuMGDF) as an adjunct to chemotherapy for adults with de novo acute myeloid leukemia. Blood. 1999;94(11):3694-3701. 
85. Schiffer CA, Miller K, Larson RA, et al. A double-blind, placebocontrolled trial of pegylated recombinant human megakaryocyte growth and development factor as an adjunct to induction and consolidation therapy for patients with acute myeloid leukemia. Blood. 2000;95(8):2530-2535.

86. Bolwell B, Vredenburgh J, Overmoyer B, et al. Phase 1 study of pegylated recombinant human megakaryocyte growth and development factor (PEG-rHuMGDF) in breast cancer patients after autologous peripheral blood progenitor cell (PBPC) transplantation. Bone Marrow Transplant. 2000;26(2):141-145.

87. Li J, Yang C, Xia Y, et al. Thrombocytopenia caused by the development of antibodies to thrombopoietin. Blood. 2001;98(12): 3241-3248.

88. Basser RL, O'Flaherty E, Green M, et al. Development of pancytopenia with neutralizing antibodies to thrombopoietin after multicycle chemotherapy supported by megakaryocyte growth and development factor. Blood. 2002;99(7):2599-2602.

89. Lollar P. Pathogenic antibodies to coagulation factors. Part one: factor VIII and factor IX. J Thromb Haemost. 2004;2:1082-1095.

90. Key NS. Inhibitors in congenital coagulation disorders. Br J Haematol. 2004;127(4):379-391.

91. Cwirla SE, Balasubramanian P, Duffin DJ, et al. Peptide agonist of the thrombopoietin receptor as potent as the natural cytokine. Science. 1997;276(5319):1696-1699.

92. de Serres M, Ellis B, Dillberger JE, et al. Immunogenicity of thrombopoietin mimetic peptide GW395058 in BALB/c mice and New Zealand white rabbits: evaluation of the potential for thrombopoietin neutralizing antibody production in man. Stem Cells. 1999;17(4): 203-209.

93. Deng B, Banu N, Malloy B, et al. An agonist murine monoclonal antibody to the human $c-M p 1$ receptor stimulates megakaryocytopoiesis. Blood. 1998;92(6):1981-1988.

94. Rice L. Drug evaluation: AMG-531 for the treatment of thrombocytopenias. Curr Opin Investig Drugs. 2006;7(9):834-841.

95. Nichol JL. AMG 531: an investigational thrombopoiesis-stimulating peptibody. Pediatr Blood Cancer. 2006;47(5 Suppl):723-725.

96. Wang B, Nichol JL, Sullivan JT. Pharmacodynamics and pharmacokinetics of AMG 531, a novel thrombopoietin receptor ligand. Clin Pharmacol Ther. 2004;76(6):628-638.

97. Broudy VC, Lin NL. AMG531 stimulates megakaryopoiesis in vitro by binding to Mpl. Cytokine. 2004;25(2):52-60.

98. Newland A, Caulier MT, Kappers-Klunne M, et al. An open-label, unit dose-finding study of AMG 531, a novel thrombopoiesis-stimulating peptibody, in patients with immune thrombocytopenic purpura. $\mathrm{Br} J$ Haematol. 2006;135(4):547-553.

99. Bussel JB, Kuter DJ, George JN, et al. AMG 531, a thrombopoiesisstimulating protein, for chronic ITP. $N$ Engl J Med. 2006;355(16): $1672-1681$.

100. Kuter DJ, Bussel JB, Lyons RM, et al. Efficacy of romiplostim in patients with chronic immune thrombocytopenic purpura: a double-blind randomised controlled trial. Lancet. 2008;371(9610): 395-403

101. George JN, Mathias SD, Go RS, et al. Improved quality of life for romiplostim-treated patients with chronic immune thrombocytopenic purpura: results from two randomized, placebo-controlled trials. $\mathrm{Br} J$ Haematol. 2009;144(3):409-415.

102. Bussel JB, Kuter DJ, Pullarkat V, Lyons RM, Guo M, Nichol JL. Safety and efficacy of long-term treatment with romiplostim in thrombocytopenic patients with chronic ITP. Blood. 2009;113(10):2161-2171.

103. Yan XQ, Lacey D, Fletcher F, et al. Chronic exposure to retroviral vector encoded MGDF (mpl-ligand) induces lineage-specific growth and differentiation of megakaryocytes in mice. Blood. 1995;86(11): 4025-4033.

104. Ulich TR, del Castillo J, Senaldi G, et al. Systemic hematologic effects of PEG-rHuMGDF-induced megakaryocyte hyperplasia in mice. Blood. 1996;87(12):5006-5015.
105. Yanagida M, Ide Y, Imai A, et al. The role of transforming growth factor-beta in PEG-rHuMGDF-induced reversible myelofibrosis in rats. Br J Haematol. 1997;99(4):739-745.

106. Chagraoui H, Komura E, Tulliez M, Giraudier S, Vainchenker W, Wendling F. Prominent role of TGF-beta 1 in thrombopoietin-induced myelofibrosis in mice. Blood. 2002;100(10):3495-3503.

107. Kuter DJ, Mufti GJ, Bain BJ, Hasserjian RP, Davis W, Rutstein M. Evaluation of bone marrow reticulin formation in chronic immune thrombocytopenia (ITP) patients treated with romiplostim. Blood. 2009; 114:3748-3756.

108. Amgen. Romiplostim package insert. 2008. http://www.nplatenexus. com/pdfs/misc/nplate_pi.pdf. Accessed on October 10, 2009.

109. Kumagai Y, Fujita T, Ozaki M, et al. Pharmacodynamics and pharmacokinetics of AMG 531, a thrombopoiesis-stimulating peptibody, in healthy Japanese subjects: a randomized, placebo-controlled study. $J$ Clin Pharmacol. 2007;47(12):1489-1497.

110. Duffy KJ, Darcy MG, Delorme E, et al. Hydrazinonaphthalene and azonaphthalene thrombopoietin mimics are nonpeptidyl promoters of megakaryocytopoiesis. J Med Chem. 2001;44(22): 3730-3745.

111. Luengo JI, Duffy KJ, Shaw AN, et al. Discovery of SB-497115, a small-molecule thrombopoietin (TPO) receptor agonist for the treatment of thrombocytopenia. Blood (ASH Annual Meeting Abstracts). 2004;104(11):2910.

112. Erickson-Miller C, Delorme E, Giampa L, et al. Biological activity and selectivity for TPO receptor of the orally bioavailable, small molecule TPO receptor agonist, SB-497115. Blood (ASH Annual Meeting Abstracts). 2004;104(11):2912.

113. Erickson-Miller CL, Delorme E, Tian SS, et al. Preclinical activity of eltrombopag (SB-497115), an oral, nonpeptide thrombopoietin receptor agonist. Stem Cells. 2009;27(2):424-430.

114. Erhardt J, Erickson-Miller CL, Tapley P. Agonist-induced platelet aggregation in vitro. ASH Annual Meeting Abstracts. 2004;104(11):3888.

115. Jenkins JM, Williams D, Deng Y, et al. Phase I clinical study of eltrombopag, an oral, non-peptide thrombopoietin receptor agonist. Blood. 2007;109:4739-4741.

116. Williams DD, Peng B, Bailey CK, et al. Effects of food and antacids on the pharmacokinetics of eltrombopag in healthy adult subjects: Two single-dose, open-label, randomized-sequence, crossover studies. Clin Ther. 2009;31(4):764-776.

117. Bussel JB, Cheng G, Saleh MN, et al. Eltrombopag for the treatment of chronic idiopathic thrombocytopenic purpura. $N$ Engl J Med. 2007;357(22):2237-2247.

118. McHutchison JG, Dusheiko G, Shiffman ML, et al. Eltrombopag for thrombocytopenia in patients with cirrhosis associated with hepatitis $\mathrm{C}$. N Engl J Med. 2007;357(22):2227-2236.

119. Bussel JB, Provan D, Shamsi T, et al. Effect of eltrombopag on platelet counts and bleeding during treatment of chronic idiopathic thrombocytopenic purpura: a randomised, double-blind, placebo-controlled trial. Lancet. 2009;373(9664):641-648.

120. GlaxoSmithKline. PROMACTA ${ }^{\circledR}$ (eltrombopag) tablets. 2008. Available from: http://www.promactacares.com/prescribing_information. pdf. Accessed on October 10, 222009.

121. Rice L. Treatment of immune thrombocytopenic purpura: focus on eltrombopag. Biologics. 2009;3:151-157.

122. Su SF, Peng B, Williams D, et al. A phase I study to investigate the pharmacokinetics (PK) and pharmacodynamics (PD) of an oral platelet growth factor (SB-559448) in healthy subjects. ASH Annual Meeting Abstracts. 2006;108(11):1072.

123. Desjardins RE, Tempel DL, Lucek R, Kuter DJ. Single and multiple oral doses of AKR-501 (YM477) increase the platelet count in healthy volunteers. ASH Annual Meeting Abstracts. 2006;108(11):477.

124. Orita T, Tsunoda H, Yabuta N, et al. A novel therapeutic approach for thrombocytopenia by minibody agonist of the thrombopoietin receptor. Blood. 2005;105(2):562-566. 
125. Frederickson S, Renshaw MW, Lin B, et al. A rationally designed agonist antibody fragment that functionally mimics thrombopoietin. Proc Natl Acad Sci U S A. 2006;103(39):14307-14312.
126. Nakamura T, Miyakawa Y, Miyamura A, et al. A novel nonpeptidyl human $\mathrm{c}-\mathrm{Mpl}$ activator stimulates human megakaryopoiesis and thrombopoiesis. Blood. 2006;107(11):4300-4307.

\section{Publish your work in this journal}

Biologics: Targets \& Therapy is an international, peer-reviewed journal focusing on the patho-physiological rationale for and clinical application of Biologic agents in the management of autoimmune diseases, cancers or other pathologies where a molecular target can be identified. This journal is indexed on PubMed Central, CAS,
Dovepress

EMBase, Scopus and the Elsevier Bibliographic databases. The manuscript management system is completely online and includes a very quick and fair peer-review system, which is all easy to use. Visit http://www.dovepress.com/testimonials.php to read real quotes from published authors. 